\title{
Study on the performance of the new high-strength steel-encased Concrete composite beam (SCCB)
}

\author{
Qiyin Shi ${ }^{1, a}$, Chao Liu ${ }^{1, b}$, Lilin Cao ${ }^{1, c}$, Zhen Wang ${ }^{1, d}$ \\ ${ }^{1}$ Department of civil engineering, Jiangsu University, Zhenjiang 212013, China \\ a shiqiyin@ujs.edu.cn, ${ }^{b}$ liucha0870925@163.com, ${ }^{c}$ cll@ujs.edu.cn, ${ }^{d}$ caolilinseu@163.com
}

Keywords: high-strength steel-encased concrete composite beam (SCCB hereafter), high-performance steel, high- strength concrete, flexural bearing capacity.

\begin{abstract}
On the basis of the theoretical study and application of ordinary steel-encased concrete composite beam, this paper will focus on a new high-strength steel-encased concrete composite beam, and mainly studies high-performance steel Q420 and Q460, as well as high-strength concrete C60 and C80. Besides, an experimental study of 5 simply-supported beams is made, and the load-deflection curves of new SCCB are analyzed. The calculation formula of load which changes with depth of section and bending strength of the cross section is also analyzed. It is suggested that the calculated results announced should be identical with the experimental results.
\end{abstract}

\section{Introduction}

With society's development, various structural forms of buildings have been built. The common structures in the $21^{\text {st }}$ century have entered the era of composite structure with high-performance steel and high-strength concrete. Compared to ordinary steel, it is clear that high-performance steel has many advantages. It not only greatly enhanced the tensile strength, but also was far better than ordinary steel in regards to corrosion resistance, among other things. The high-strength concrete has high strength, less creep, and has high resistance corrosion, seepage and wear and tear. It is also not so easy to segregate when the building is under construction. It has a relatively uniform quality and is more suitable for using in a harsh environment. In essence, applying high strength materials into composite beams not only strengthens its bearing capacity but also can save a large quantity of material, extending the life of the structure and its maintenance cycle, and thus we get a better economic effect from it overall. Therefore, it is meaningful to investigate this kind of composite beam [1].

\section{Experimental study}

Test profile. In order to investigate the mechanical properties of SCCB, Five specimens are designed according to the simplified plastic calculation method and theory of elasticity. The main variation parameters are steel strength, concrete strength and the section size of the steel beam.

Full shear connection is adopted. Loading mode is three points loading. See Gra.1.

Gra.1. Designed parameters of the sample

\begin{tabular}{|c|c|c|c|}
\hline $\begin{array}{c}\text { Serial } \\
\text { number }\end{array}$ & $f_{c k} / M P a$ & Shear action & Other measures \\
\hline HSCB 1 & 51 & $\begin{array}{c}\text { Flange bolt } \$ 16 @ 200 \\
\text { high strength bottom } \\
\text { boltM10.9@400shear stirrup } \$ 8 @ 100 / 200\end{array}$ & $\begin{array}{l}\text { Flange valgus } 60 \mathrm{~mm} \\
2 \$ 12 \text { structure reinforcement } 2 \$ 16 \text { fire } \\
\text { reinforcement }\end{array}$ \\
\hline HSCB 2 & 51 & $\begin{array}{c}\text { Flange bolt } \$ 16 @ 200 \\
\text { high strength bottom } \\
\text { boltM10.9@400shear stirrup } \$ 8 @ 100 / 200\end{array}$ & $\begin{array}{c}\text { Flange valgus60mm } \\
2 \$ 12 \text { structure reinforcement } 2 \$ 16 \text { fire } \\
\text { reinforcement }\end{array}$ \\
\hline HSCB 3 & 62.7 & $\begin{array}{c}\text { Flange bolt } \$ 16 @ 200 \\
\text { high strength bottom } \\
\text { boltM10.9@400shear stirrup } \$ 8 @ 100 / 200\end{array}$ & $\begin{array}{c}\text { Flange valgus60mm } \\
2 \$ 12 \text { structure reinforcement } 2 \$ 16 \text { fire } \\
\text { reinforcement }\end{array}$ \\
\hline
\end{tabular}




\begin{tabular}{|c|c|c|c|}
\hline HSCB 4 & 51 & $\begin{array}{c}\text { Flange bolt } \$ 16 @ 200 \\
\text { high strength bottom } \\
\text { boltM10.9@400shear stirrup } \$ 8 @ 100 / 200\end{array}$ & $\begin{array}{c}\text { Flange valgus60mm } \\
2 \$ 12 \text { structure reinforcement 2 } \\
\text { reinforcement }\end{array}$ \\
\hline HSCB 5 & 62.7 & $\begin{array}{c}\text { Flange bolt } \$ 16 @ 200 \\
\text { high strength bottom } \\
\text { boltM10.9@400shear stirrup } \$ 8 @ 100 / 200\end{array}$ & $\begin{array}{c}\text { Flange valgus60mm } \\
2 \$ 12 \text { structure reinforcement 2 } \\
\text { reinforcement }\end{array}$ \\
\hline
\end{tabular}

Experiment is conducted in a way of loading manually. Loading devices are two hydraulic jacks with weight 50-ton (which have been calibrated).The load is measured by a pressure sensor (which has 30tons) which is linked with hydraulic jacks. Reaction frame is laid in the loading place and is fixed into geosynclines and each hydraulic jack is between reaction frame and composite beam. Synchronous loading is adopted during experiment and pre-loaded weight is $2 \mathrm{KN}$. Meter will be checked to ensure that it works well. $20 \mathrm{KN}$ is taken as a load grade during the formal test. Some measuring devices like force, displacement strain and rotation angle are laid in each component.

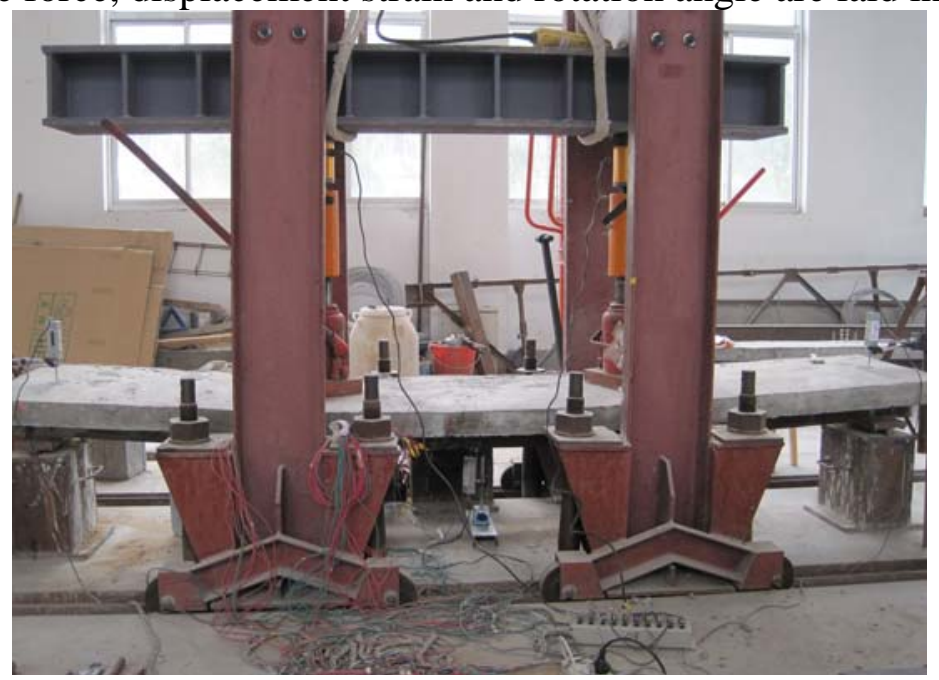

Fig.1 Experiment setting

Experiment process and failure phenomena. The loading process and failure phenomena of the five simply supported composite beam specimens are similar. This paper will illustrate it by taking HSCB1 as example. Natural bond force and bolts will work together to resist longitudinal shear force of the flange plates of concrete and interfaces of steel beams during initial stage of loading. Composite beam will make large sound when the loading weight reaches $60 \mathrm{kN}$, which indicates that chemical bonding force begins to be destroyed, longitudinal shear force of interfaces begin to be undertaken by bolts themselves. When the loading weight is up to $80 \mathrm{Kn}$, slip crack will appear at the border of the side of concrete and the interfaces of steel beams, but they can still work together. The bottom steel plate will yield with the increase of the load. The deflection development rate begins to be higher than the loading rate, the flange side of the composite beam begins to appear the first longitudinal crack and run slowly along the transverse with crack noise of the concrete slab. The pure bending section surface of concrete begins to pluck up clearly when the load reaches $160 \mathrm{kN}$ and the scope the expanding area continuously increases with the increase the load, which means that the specimens will reach its ultimate load. As the load weight becoming heavier, the midspan of pure bending section of concrete beam will be crushed and simply supported beam will be damaged and lose carrying capacity.

The test results. The test results is shown as table 2 and $F_{y}$ is equivalent yield strength of steel beam whole section when steel beam attain yield strength, $M_{y t}$ and $M_{u t}$ represent yield strength of the midspan and measured value of moment of the beam respectively and $\delta_{y t}$ and $\delta_{u t}$ represent measured value of span deflection respectively, $M_{u}$ represent ultimate flexural capacity of the beam which was calculated according to simplified theory of plasticity. 
Gra.2 Test parameters and results

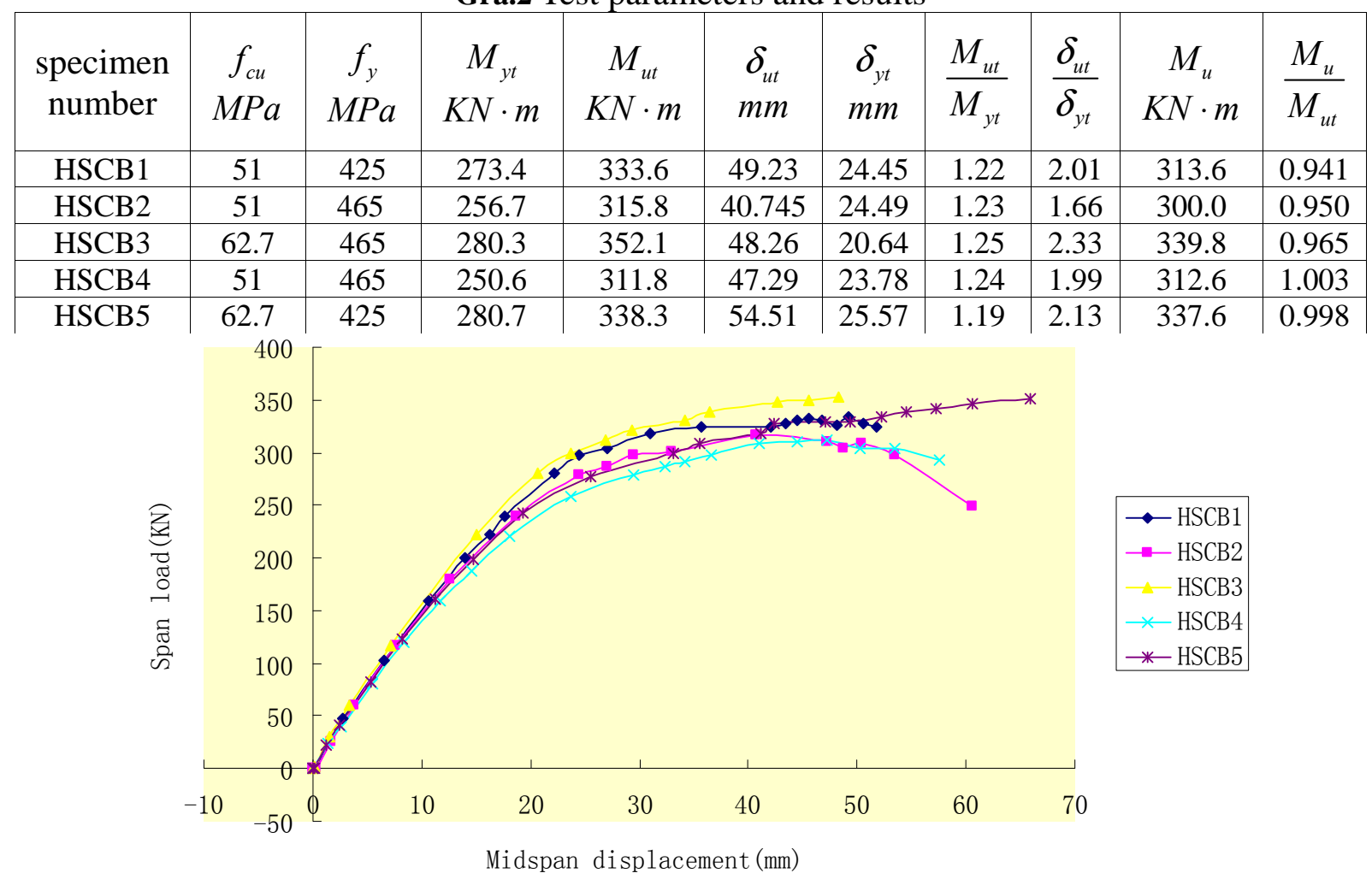

Fig.2 Experiment relationship curves of moment and deflection

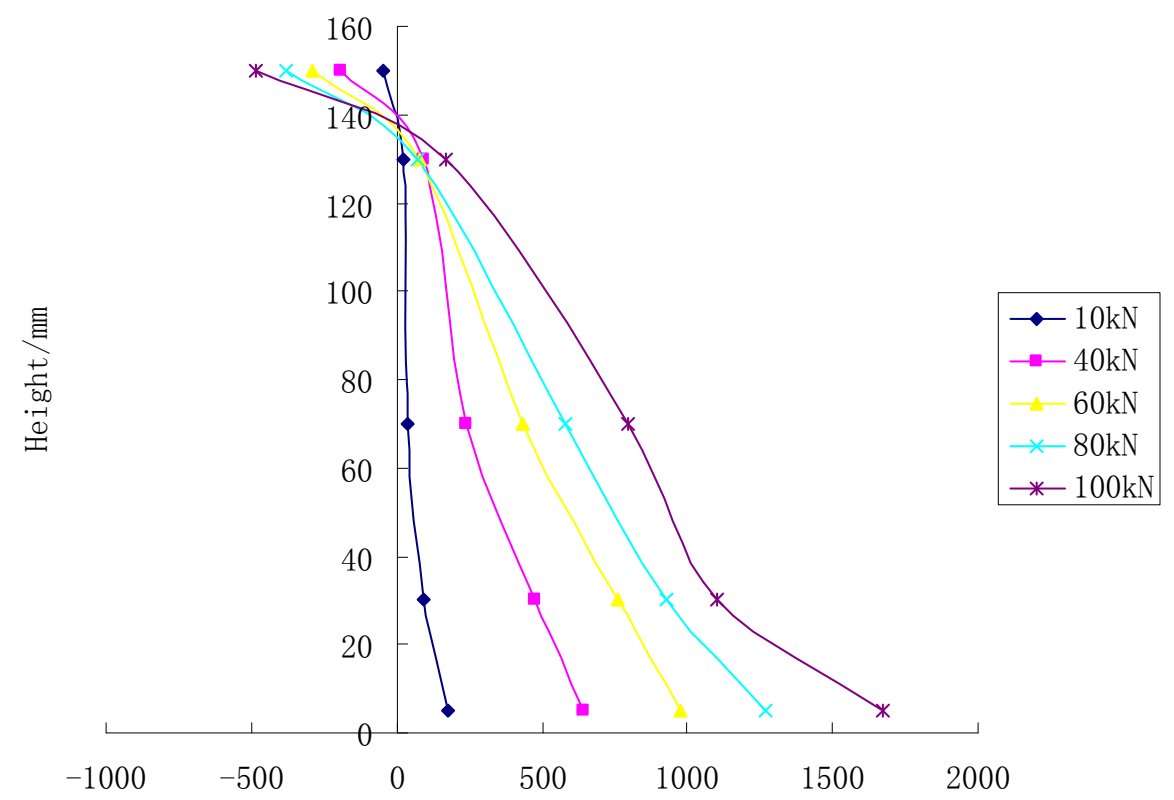

Fig.3 Distribution of strain along the height of cross section at middle span

Load-deflection curve. The curves of load-deflection----midspan of the simply supported composite beam are shown in Fig 2. Steel plate has good ductility, so the crush of the concrete is taken as the standard of destruction. According to the above chart, the load - deflection curve of composite supporting beam of highly strengthened enclosing steel and highly reinforced concrete was divided into three stages.

1) Elastic working stage: The stiffness of the cross sections of the whole specimen remains the same during the process from the beginning. Loading is loaded to the crack of tensile region. The beam could be approximately thought as an elastic homogeneous one and the load---midspan deflection curve is approximately a linear relationship.

2) Elastoplastic working stage: The stiffness of the cross sections of the composite beam begins to gradually decline after the yieldingness occurs on the bottom of the steel beam and the curve 
becomes gentle. However, no segment of the curve descends considerable. The curve has no descent stage till it goes to the breaking stage, which indicates that the beam has good ductility.

3) Destruction stage: Cross-in flange plates of the concrete will be crushed partially after the bending moment reaches the ultimate flexural bearing capacity and this will finally lead to the drastic fall of the flexural bearing capacity.

Load change along the height of the cross section . As demonstrated in Fig.3, the composite beam roughly accords with the assumption of flat section.

\section{Theoretical analysis}

The formula of flexural Capacity forces. The experimental phenomena showed that the majority of section of the steel beam reached yield stage when composite beam reached ultimate bearing capacity. The flexural capacity can be figured out by simplified theory of plasticity [2]. In the experiment, no sooner had the composite beam attained the ultimate bearing capacity than the most part of the cross section of the steel beam was in yielding stage. Therefore, the flexural capacity could be calculated by simplified plasticity theory. The neutral axis is in concrete flange plates and the whole cross section of the steel beam yield by tension.

We can get the result according to equilibrium conditions $\sum x=0$ and moment equilibrium condition $\sum M=0$ from bottom flange core of the steel beam.

$$
\begin{aligned}
& \sum x=0 \quad \alpha_{1} f_{c} b_{c f} x=f_{t b y} \dot{A}_{t b}+2 f_{t w y} A_{t w}+4 f_{t w y} A_{t f} \\
& \sum M=0 \quad M \leq M_{u}=\alpha_{1} f_{c} b_{c f} x\left(h_{0}-x / 2\right)-f_{t w y}\left(A_{t w}+2 A_{t f}\right)\left(h_{t w}+t_{t b}\right) \\
& A_{t b}=b \times t_{\mathrm{tb}} 、 A_{t w}=h_{t w} \times t_{t w}, A_{t f}=b_{t f} \times t_{t w}
\end{aligned}
$$

And $M$ is designing bending moment, $\mathrm{f}_{\mathrm{c}}$ is the design value of axial compressive strength , $\mathrm{b}_{c f}$ is Width of the concrete flange plate, $x$ is Plastic zone height of concrete flange plate, $f_{t b y}$ 、 $f_{t w y}$ is Yield strength design values of steel, $A_{t b} 、 A_{t w} 、 A_{t f}$ are Cross-sectional areas of the bottom of the steel plate , Side steel plate and extended portion of flange of the steel beam respectively, $b_{t b}$ 、 $b_{t w} 、 b_{t f}$ are thickness of the bottom steel plate, side steel plate and extended portion of flange of the steel.Stress coefficient $\alpha$ of high strength concrete is determined by Concrete Structure Design Code GB50010-2010)[3]

The experimental comparison, which is based on measured strength of the concrete and flexural capacity are calculated by the method of the simplified plastic theory. And it also shows that measured results and calculated values coincide very well with these composite beams in which thickness of the cross sections are the same, for these composite beams' bottom plates are thought that the calculated value are on the safe side, and is the reason that the bottom plate will play a major role in all bearing capacity factors. This kind of cross section should increase Stress coefficient $\alpha$ when we calculate. In general calculated value is on the safe side, so it could be concluded from fig2 that strengthening effect of a web of steel beams can increase the ultimate flexural capacity and create a slip effect which can reduce ultimate flexural capacity[4]. Therefore, the affection on the ultimate flexural capacity of the new composite beam of highly strengthened steel and highly reinforced concrete caused by the slip effect is negligible. Simplified plasticity theory is still applicable [5].

Parameter analysis. The contrast of HSCB1 and HSCB2 in Fig2 shows that we can not increase ultimate flexural capacity and ductility by the way of increasing the steel strength, when cross section and the strength of the concrete are the same. From the contrast of element 2 and element 3 we know that flexural capacity can be increased by increasing concrete strength when other factors are the same. from the contrast element 2 and element 4 we know that the change of cross section has little effect on flexural capacity of composite beam when the strength of concrete and steel are 
the same. The main factors are the performance of a variety of materials which are affected.

\section{Conclusion}

We analyzed testing process, failure phenomena and experimental results through these experiments of five simply supported beams and verified a more reliable carrying capacity calculation formula; we put forward a scheme by comparatively analyzing these parameters of the supported beams. We draw these following conclusions:

1) A new type high-strength steel and high-strength concrete composite beam has high flexural capacity and ductility, but is not a reasonable and economical method to increase the strength of composite beam by increasing the strength of materials blindly.

2) The bending capacity can be calculated by the method of simplified plastic theory, with the bottom plate having a thicker section a good flexural bearing capacity and ductility, in which stress coefficient $\alpha$ should be increased properly when it is calculated.

\section{Acknowledgements}

The authors are very grateful to the support of National Training Programs of Innovation and Entrepreneurship for Undergraduates (No.201210299026).

\section{References}

[1] Jianguo Nie, Hongquan Wang, Ying Tan, Ge Chen. Experimental study on composite steel-Hsc beams. Journal of Building structures, Feb.2004, Vol.25.No1. (In Chinese).

[2] Guoliang Bai, Fuhua Qin Design and principal of SRC structures. Shanghai, Science and Technology Press, 2000. (In Chinese).

[3] GB50010-2010 code for design of concrete structures [S] (In Chinese).

[4] Jianguo Nie, Jumin Shen. Slip effect on strength of composite steel-concrete beams [J]. China Civil Engineering Journal 1997, 30 (1): 31-36. ( In Chinese)

[5] Jianguo Nie, Hongyou Li, Liang Tang. Experimental study on HSS-concrete composite beams. Journal of Building structures, 2009,30 (2):64-69(In Chinese). 